\begin{tabular}{|c|c|c|}
\hline BIODIK & $\begin{array}{c}\text { BIODIK: Jurnal IImiah Pendidikan Biologi } \\
\text { ISSN 2580-0922 (online), ISSN 2460-2612 (print) } \\
\text { Volume 7, Nomor 02, Tahun 2021, Hal. 33-44 } \\
\text { Available online at: } \\
\text { https://online-journal.unja.ac.id/biodik }\end{array}$ & BIODIK \\
\hline
\end{tabular}

Research Article

OPEN ACCESS

\title{
Identifikasi Miskonsepsi Peserta Didik Menggunakan Two-Tier Test Berbantuan Certainty of Response Index
}

\author{
(Misconception Identification of Students using Two-Tier Test Assisted by Certainty of \\ Response Index)
}

\author{
Herfine Fristiansa Firman*, Jujun Ratnasari, Sistiana Windyariani \\ Prodi Pendidikan Biologi, Fakultas Keguruan IImu Pendidikan \\ Universitas Muhammadiyah Sukabumi \\ JI. R. Syamsudin, S.H. No. 50, Kec. Cikole, Kota Sukabumi, 43113, Indonesia \\ ${ }^{*}$ Corresponding Author: herfinefristiansaf@gmail.com
}

\begin{tabular}{|c|c|}
\hline Informasi Artikel & ABSTRACT \\
\hline $\begin{array}{l}\text { Submit: } 26-02-2021 \\
\text { Diterima: } 03-04-2021 \\
\text { Dipublikasikan: } 01-06-2021\end{array}$ & $\begin{array}{l}\text { The misconception is a problem in learning and it is very necessary to solve it so that } \\
\text { learning is better. Students who are identified with misconceptions on material } \\
\text { concepts can make it difficult for them to believe new concepts that are true. The } \\
\text { purpose of this study is to identify the existence of misconceptions in students in an } \\
\text { ecosystem material concept that they have studied previously. This study uses a } \\
\text { descriptive method with a quatitative approach. The research was conducted at } \\
\text { Senior High School (SMA) in Sukabumi Regency. The subjects studied were } 36 \\
\text { students of class XI MIPA 5. The instrument used was } 45 \text { multiple choice questions } \\
\text { with the help of the Certainty of Response Index (CRI). The results showed the } \\
\text { understanding of students in the percentage of conceptual understanding (PK), } \\
\text { understanding the concept of being unsure (PKKY), Misconception (M), and not } \\
\text { knowing the concept (TTK) were } 20 \%, 6 \%, 32 \%, 42 \% \text {. The highest misconception } \\
\text { percentage at level } 1 \text { after testing was at the indicator describing the relationship } \\
\text { between ecosystem components (60\%), level } 2 \text { understanding the pattern of } \\
\text { interactions between organisms (53\%), and the lowest on indicators showing } \\
\text { succession definition (12\%). Therefore, misconceptions among students in } \\
\text { ecosystem material need to be eliminated by choosing the right method, learning } \\
\text { model, and approach. }\end{array}$ \\
\hline & $\begin{array}{l}\text { Keywords :Misconceptions, Motion Ecosystem, Two-Tier Test Assisted by Certainty } \\
\text { of Response Index }\end{array}$ \\
\hline Penerbit & ABSTRAK \\
\hline $\begin{array}{l}\text { Program Studi Pendidikan Biologi } \\
\text { FKIP Universitas Jambi, } \\
\text { Jambi- Indonesia }\end{array}$ & $\begin{array}{l}\text { Miskonsepsi merupakan permasalahan di dalam pembelajaran dan sangat perlu } \\
\text { dilakukan penyelesaian agar suatu pembelajaran lebih baik. Peserta didik yang } \\
\text { teridentifikasi miskonsepsi pada suatu konsep materi dapat membuat mereka sulit } \\
\text { dalam mempercayai konsep baru yang benar. Tujuan dari penelitian ini yaitu untuk } \\
\text { mengidentifikasi adanya miskonsepsi pada peserta didik dalam suatu konsep materi } \\
\text { ekosistem yang telah mereka pelajari sebelumnya. Penelitian ini menggunakan } \\
\text { metode deskriptif dengan pendekatan kuantitatif. Penelitian dilakukan di Sekolah } \\
\text { Menengah Atas (SMA) yang berada di Kabupaten Sukabumi. Subjek yang di teliti } \\
\text { merupakan } 36 \text { peserta didik kelas XI MIPA 5. Instrumen yang digunakan berupa } 45\end{array}$ \\
\hline
\end{tabular}


soal pilihan ganda beralasan berbantuan Certainty of Respon Index (CRI). Hasil penelitian menunjukan pemahaman peserta didik dalam persentase paham konsep (PK), paham konsep kurang yakin (PKKY), Miskonsepsi (M) dan Tidak tahu konsep (TTK) adalah $20 \%, 6 \%, 32 \%, 42 \%$. Perolehan persentase miskonsepsi tertinggi pada level 1 setelah pengujian berada pada indikator mendeskripsikan hubungan antar komponen ekosistem (60\%), level 2 memahami pola interaksi antar organisme $(53 \%)$ dan terendah pada indikator menunjukan devinisi suksesi (12\%). Maka dari itu miskonsepsi pada peserta didik dalam materi ekosistem perlu dihilangkan dengan memilih metode, model pembelajaran dan pendekatan yang tepat.

Katakunci : Miskonsepsi, Materi Ekosistem, Two-Tier Test berbantuan Certainty of Response Indeks

\section{PENDAHULUAN}

Dunia pendidikan saat ini sedang menjadi perhatian terutama mengenai permasalahan miskonsepsi pada peserta didik (Anjarsari, 2018). Miskonsepsi telah banyak dikaji oleh berbagai peneliti terutama pada bidang sains (Patil et al., 2019). Çepni et al., (2017) menjelaskan bahwa pemahaman konsep pada setiap peserta didik merupakan aspek penting dari keberhasilan suatu pembelajaran. Tujuan utama peneliti melakukan studi miskonsepsi adalah untuk mengetahui seberapa banyak peserta didik memahami suatu konsep pembelajaran dan seberapa banyak yang memiliki miskonsepsi pada materi yang diteliti (Gurel et al., 2015).

Miskonsepsi merupakan permasalahan didalam suatu kegiatan pembelajaran sehingga miskonsepsi sangat perlu diatasi agar hilang dan suatu pembelajaran kembali baik (Nikmah \& Suyono, 2015). Penyebab adanya miskonsepsi yaitu akibat penggunaan konsep yang kurang tepat (Pebrianti, 2015). Peserta didik cenderung membangun pemikiran mereka berdasarkan pengalaman atau dalam proses belajar disekolah (Gurel et al., 2015). Peserta didik juga dapat dikatakan teridentifikasi miskonsepsi jika mereka memiliki pemahaman dan pengimplementasian dalam suatu konsep dengan kesalahan berulang (Ikram et al., 2018).

Pebrianti, (2015) dalam penelitiannya memperoleh hasil miskonsepsi sebesar 40\%, menurutnya pembelajaran sains dianggap suatu materi yang sulit dipahami oleh peserta didik karena memiliki banyak konsep - konsep yang rumit sehingga selalu teridentifikasi miskonsepsi dalam setiap konsepnya. Tekayya, (2002) berpendapat konsep ekologi dalam materi biologi merupakan salah satu materi yang sangat sering teridentifikasi miskonsepsi setelah konsep respirasi, fotosintesis dan genetika. Peserta didik mempelajari materi ekologi melalui gagasan yang diciptakan dari pemahaman dunia nyata mereka dan berdasarkan pengalaman yang tidak ilmiah (Jahidin \& Rabani, 2018).

Chyleńska \& Rybska, (2019) berpendapat dalam artikelnya bahwa miskonsepsi dapat terlihat dari 3 gagasan utama seperti pengetahuan materi yang kurang tepat serta peserta didik masih mempercayai konsep lama, peserta didik yang belum bisa mengubah konsepnya, pemikiran peserta didik yang belum terstruktur dan belum sistematis. Miskonsepsi seharusnya dapat diatasi sejak awal karena dapat menjadi langkah awal kesalahan dalam pembelajaran. Keberadaan miskonsepsi itu 
sendiri tidak banyak diketahui baik oleh pengajar ataupun peserta didik maka diperlukan instrumen yang tepat agar pendidik dapat mengidentifikasi adanya miskonsepsi didalam pemikiran peserta didik.

Anggrayni \& Ermawati, (2019) menyatakan bahwa miskonsepsi dapat di identifikasi dengan menggunakan test diagnostic multiple choice, test tersebut telah digunakan oleh beberapa peneliti dalam mengidentifikasian miskonsepsi pada peserta didik. Test yang memiliki struktur alternatif jawaban terhadap suatu pertanyaan (Qurrota \& Nuswowati, 2018). Test diagnostik memiliki 4 jenis cara untuk pengidentifikasian mulai dari satu tingkat jawaban sampai empat jawaban yang sangat kompleks (Hermita et al., 2017). Berbagai macam cara tersebut dapat dijadikan suatu pengidentifikasian miskonsepsi pada peserta didik namun miskonsepsi dapat lebih mudah di identifikasi dengan Two- Tier Test (Grospietsch \& Mayer, 2018). Two-Tier memiliki kelebihan dalam mengidentifikasi miskonsepsi karena peserta didik tidak hanya diberikan soal namun diberikan alasan mengapa peserta didik memilih jawaban tersebut (Kurniasih \& Haka, 2017).

Hakim et al., (2012) menyatakan bahwa karakteristik peserta didik di Indonesia seringkali menjawab dengan ragu - ragu. Hal tersebut mengharuskan pengidentifikasian menggunakan skala pengukuran yang akurat. Pemodifikasian skala pengukuran Certainty of Response Index (CRI) yang sebelumnya telah dikembangkan oleh Hasan et al. (1999). Kelebihan dari metode pengukuran ini adalah pendidik dapat mengidentifikasi secara objektif (Sinta et al., 2020). Skala CRI dapat membedakan mana peserta didik yang mengetahui konsep dan yang memiliki miskonsepsi (Qurrota \& Nuswowati, 2018). CRI tidak hanya digunakan untuk pengidentifikasi miskonsepsi saja tetapi dapat digunakan untuk mengetahui kategori pemahaman peserta didik (Alonemarera, 2020).

Waluyo et al., (2019) menyatakan bahwa CRI memiliki kelebihan dan kekurangan, kelebihan $\mathrm{CRI}$ yaitu dapat digunakan dalam beberapa tingkat pendidikan dan kekurangannya mengarah pada kejujuran peserta didik. Hakim et al., (2012) menyatakan bahwa kategori pemahaman siswa dibagi menjadi 4 kategori yaitu paham konsep (PK), paham konsep kurang yakin (PKKY), miskonsepsi (M), dan tidak tahu konsep (TTK). Salah satu cara mengatasi miskonsepsi dapat dengan cara memilih metode, model dan pendekatan pembelajaran yang tepat (Grospietsch \& Mayer, 2018).

Berdasarkan uraian diatas peneliti tertarik untuk mengetahui miskonsepsi dalam materi ekosistem menggunakan test diagnostik Two-Tier Test berbantuan Certainty of Response Index (CRI) pada peserta didik Sekolah Menengah Atas (SMA) di Kabupaten Sukabumi. Penelitian ini bertujuan untuk mengetahui seberapa banyak peserta didik memiliki pemahaman konsep sesuai kriteria yang di modifikasi oleh Hakim, (2012) terutama pada kriteria miskonsepsi (M).

\section{METODE PENELITIAN}

Penelitian ini menggunakan metode deskriptif dengan pendekatan kuantitatif. Penelitian dilakukan di salah satu Sekolah Menengah Atas (SMA) berlokasi di Kabupaten Sukabumi. Subjek penelitian merupakan 36 peserta didik kelas XI MIPA 5 yang telah mempelajari materi ekosistem dikelas sebelumnya. Penelitian ini dilakukan pada tanggal 20 Maret 2021 dan prosedur penelitian dilakukan secara online menggunakan Google Form dengan jumlah 45 soal yang mencakup 18 indikator pembelajaran dalam bentuk soal Two-Tier Test berbantuan Certainty of Response Index (CRI). Waktu pengerjaan 60 menit di luar jadwal kegiatan belajar mengajar. Instrumen yang digunakan 
merupakan instrumen untuk mengidentifikasi keberadaan miskonsepsi serta pemahaman peserta didik terhadap konsep materi ekosistem. Setiap sekala CRI berskala 6 dari (0-5) yang digagas oleh (Tayubi, 2005). Dapat dilihat pada Tabel 1.

Tabel 1 Skala Certainty of Response Index (CRI)

\begin{tabular}{cc}
\hline CRI & Kriteria \\
\hline 5 & Sangat Paham \\
\hline 4 & Hampir Paham \\
\hline 3 & Yakin \\
\hline 2 & Tidak Yakin \\
\hline 1 & Sebagian Jawaban Menduga - duga \\
\hline 0 & Seluruh Jawaban Menduga - duga \\
\hline
\end{tabular}

(Tayubi, 2005)

Perolehan hasil data kuantitatif yang telah diperoleh kemudian diolah dan dianalisis. Menggunakan kategori pemahaman yang telah dimodifikasi oleh (Hakim et al., 2012). Dapat dilihat pada Tabel 2.

Tabel 2 Kategori Pemahaman Konsep Peserta Didik

\begin{tabular}{ccccc}
\hline First tier (Jawaban) & $\begin{array}{c}\text { Second tier } \\
\text { (Alasan) }\end{array}$ & Nilai CRI & Deskripsi & Kode \\
\hline Benar & Benar & $>2,5$ & Paham Konsep & PK \\
\hline Benar & Benar & $<2,5$ & Paham Konsep Kurang Yakin & PKKY \\
\hline Benar & Salah & $>2,5$ & Miskonsepsi & M \\
\hline Benar & Salah & $<2,5$ & Tidak Tahu Konsep & TTK \\
\hline Salah & Benar & $>2,5$ & Miskonsepsi & M \\
\hline Salah & Benar & $<2,5$ & Tidak Tahu Konsep & TTK \\
\hline Salah & Salah & $>2,5$ & Miskonsepsi & M \\
\hline Salah & Salah & $<2,5$ & Tidak Tahu Konsep & TTK \\
\hline
\end{tabular}

(Hakim,2012)

Analisis dilakukan agar setiap pemahaman peserta didik terhadap materi ekosistem terutama pada masalah miskonsepsi dapat terdeteksi. Pendidik dapat mengetahui setiap pemahaman peserta didik sesuai tingkat pemahaman CRI yaitu paham konsep (PK), paham konsep kurang yakin (PKKY), miskonsepsi (M) dan tidak tahu konsep (TTK).

\section{HASIL PENELITIAN DAN PEMBAHASAN}

Penelitian miskonsepsi di SMA dalam materi ekologi merupakan hal yang penting karena pengidentifikasian tersebut dapat memperbaiki pemahaman peserta didik (Nurhidayah et al., 2020). Penelitian ini menggunakan soal test yang terbagi menjadi 18 indikator materi ekosistem dengan soal sebanyak 45 butir. Pengujian kepada 36 peserta didik kelas XI MIPA 5. Hasil berdasarkan test soal dalam bentuk Two-Tier Test berbantuan Certainty of Response Index (CRI). Total keseluruhan rata rata yang diperoleh peserta didik dalam test yaitu 20\%,6\%, $34 \%$ dan $45 \%$ sesuai dengan kategori pemahaman peserta didik menurut Hakim (2012). Dapat dilihat pada Gambar 1. 


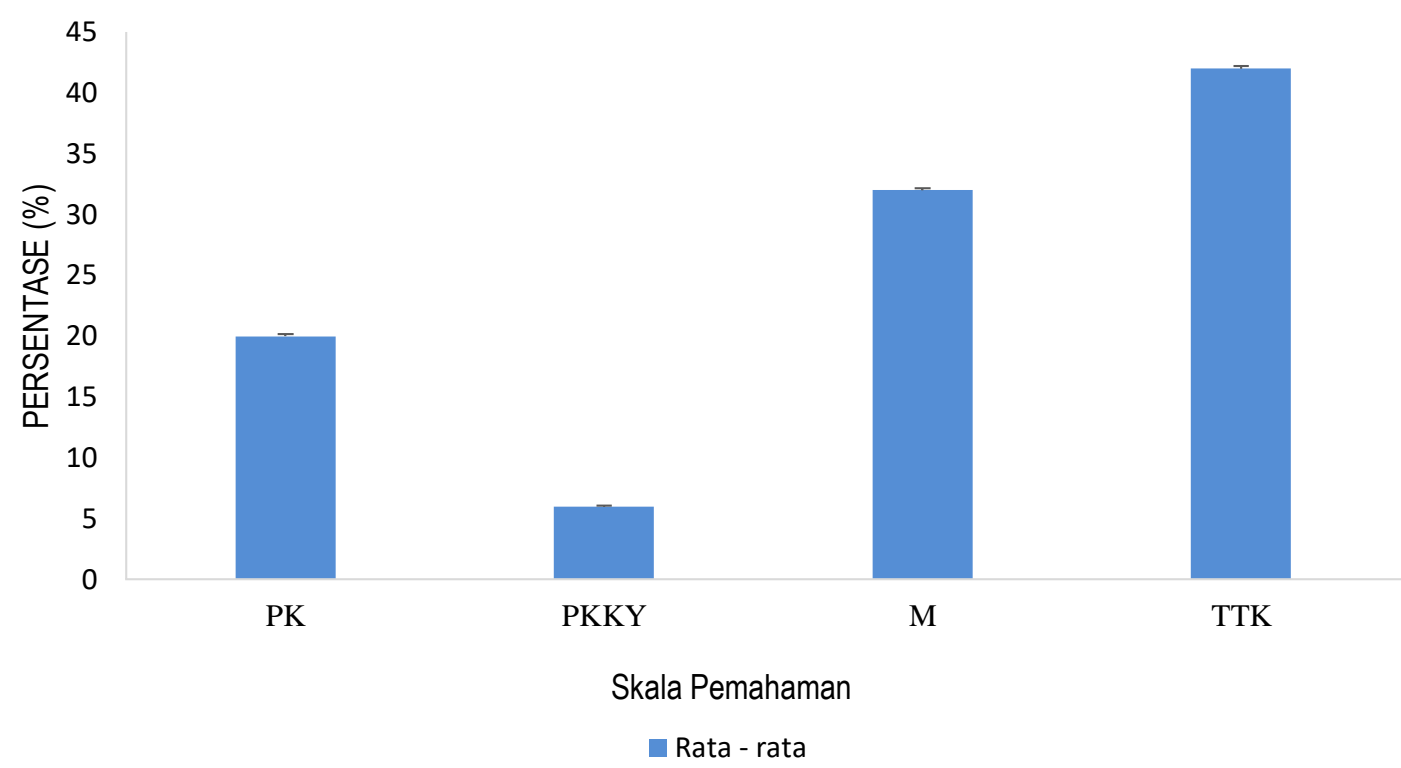

Gambar 1 Diagram Interpretasi Hasil Keseluruhan Jawaban

Hasil rata - rata menunjukan bahwa peserta didik memiliki miskonsepsi sebesar $32 \%$ perolehan ini menempati urutan ke dua terbanyak setelah pemahaman tidak tahu konsep (TTK) sebesar $42 \%$. Maesyarah et al., (2015) menyatakan bahwa peserta didik yang mengalami ketidak tahuan konsep dikarnakan pengetahuan yang mereka dapatkan seperti menerima, mengingat dan menghafal tidak dapat bertahan lama. Peserta didik yang memahami konsep (PK) hanya 20\% sedangkan paham konsep tidak yakin (PKKY) sebesar 6\%. Ramadhani \& Hasanuddin, (2016) menjelaskan bahwa ilmu sains terutama pada ilmu biologi dibutuhkan pemahaman konsep (PK) yang tinggi. Setiap pemahaman peserta didik terhadap konsep biologi dalam suatu materi maka peserta didik dapat memahami konsep materi selanjutnya. Perolehan hasil berdasarkan indikator pembelajaran dalam identifikasi miskonsepsi.

Standar deviasi (SD) merupakan nilai statistik yang biasa digunakan dalam menentukan sebaran dari sebuah sampel. Standar deviasi (SD) dari sekumpulan data yang sebanding dengan 0 menandakan semua nilai tersebut sama dan nilai yang lebih besar dari 0 menandakan bahwa data jauh dari rata - rata (mean) (Desain et al., 2019). Berdasarkan hasil persentase nilai standar deviasi (SD) paham konsep (PK), paham konsep kurang yakin (PKKY), miskonsepsi (M) dan tidak tahu konsep (TTK) sebesar 0,181, 0,074, 0,184 dan 0,206 yang dimana nilai antara rata - rata (mean) suatu sebaran dari sebuah sampel memiliki nilai yang sama. Standar deviasi (SD) tertinggi dari pengolahan data dimiliki oleh skala tidak paham konsep (TTK) sebesar 0,204 dan nilai terendah dimiliki oleh skala paham konsep kurang yakin (PKKY) sebesar 0,074 yang menjadikan TTK sebagai sebaran terjauh dan PKKY sebagai terdekat dari rata - rata (mean) diatara seluruh kategori pemahaman. 


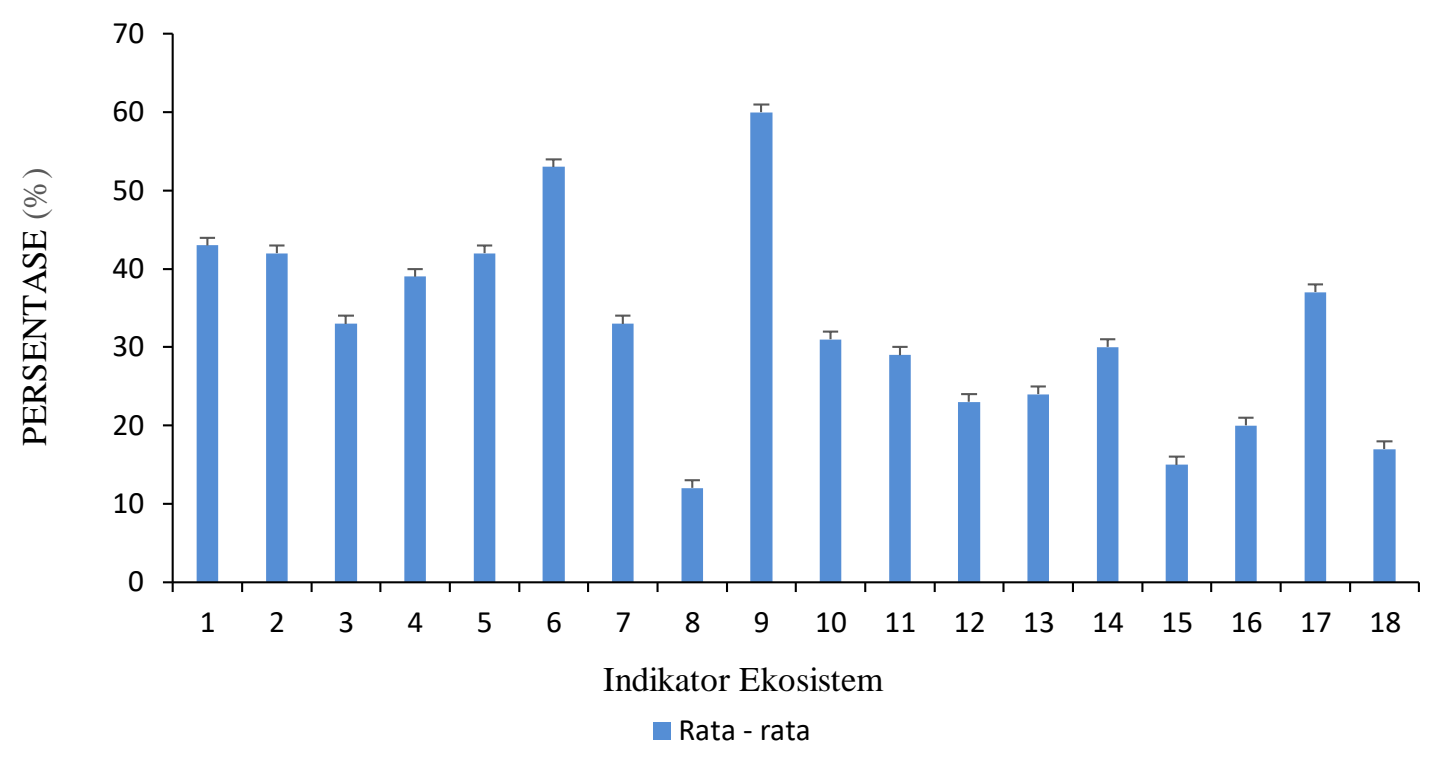

Gambar 2 Hasil Identifikasi Jawaban Peserta Didik setiap Indikator Pembelajaran

\section{Keterangan Indikator :}

1. Menyebutkan Komponen Penyusun Ekosistem

2. Mengidentifikasi Hubungan Antar Komponen Ekosistem

3. Mengidentifikasi Aliran Energi Dalam Ekosistem

4. Menyebutkan Pengertian Dan Ciri Pengurai

5. Memahami Pola Interaksi Antar Ekosistem

6. Memahami Pola Interaksi Antar Organisme

7. Memahami Penggolongan Satuan Makhluk Hidup

8. Menunjukan Definisi Suksesi

9. Mendeskripsikan Hubungan Interaksi Antar Komponen Ekosistem

10. Mengaplikasikan Pengetahuan Fenomena Interaksi

11. Menyelidiki Interaksi Antar Komponen Ekosistem

12. Menentukan Tipe Simbiosis Pada Interaksi Antar Komponen Ekosistem

13. Menganalisis Peranan Ekosistem Dalam Aliran Energi Dan Biogeokimia

14. Mengkategorikan Tipe Ekosistem Darat

15. Menganalisis Proses Suksesi

16. Menyimpulkan Keanekaragaman Makhluk Hidup

17. Meyimpulkan Interaksi Komponen Ekosistem

18. Menyimpulkan Aliran Energi Dalam Daur Materi

Berdasarkan Gambar 2 terlihat bahwa persentase miskonsepsi tertinggi level 1 berada pada indikator ke 9 yaitu mendeskripsikan hubungan antar komponen ekosistem sebanyak (60\%) dikarenakan peserta didik belum dapat memahami konsep dalam interaksi antar ekosistem dan peserta didik beranggapan bahwa energi terbesar berada pada manusia, sedangkan tertinggi di level 2 berada pada indikator ke 6 yaitu memahami pola interaksi antar organisme sebanyak (53\%) dikarenakan peserta didik terkecoh oleh gambar pada soal dan peserta didik belum memahami setiap perbedaan ciri dari interaksi antar organisme. Persentase terendah dalam pengidentifikasian miskonsepsi berada pada indikator ke 8 yaitu menunjukan definisi suksesi sebanyak (12\%). Hasil ini diperoleh dari jawaban 
peserta didik dalam kesalahan menjawab soal dari 1 tingkat pertanyaan dan tepat dalam 1 tingkat alasan dengan skala CRI diatas 2,5 atau skala 3-5.

Nilai standar deviasi (SD) terbesar level 1 dimiliki oleh indikator 17 yaitu menyimpulkan interaksi antar komponen ekosistem sebesar 0,219, level tertinggi ke 2 dimiliki oleh indikator 16 yaitu menyimpulkan keanekaragaman makhluk hidup sebesar 0,1999 dan nilai terendah dimiliki oleh indikator 18 yaitu menyimpulkan aliran energi dalam daur materi sebesar 0,065. Standar deviasi dari seluruh indikator memiliki nilai 0 yang menjadikan semua nilai memiliki sebaran yang tidak jauh dari nilai rata rata (mean).

Pendidik merupakan salah satu yang memiliki peran penting dalam terjadinya miskonsepsi pada peserta didik. Cara pembelajaran yang dipakai oleh pendidik menggunakan metode Discovery Learning pada sub materi tertentu tanpa adanya pelaksanaan praktikum dapat membuat peserta didik kurang memahami konsep (Purwanti \& Kuntjoro, 2020). Miskonsepsi sangat sulit dihilangkan jika pembelajaran masih menggunakan pembelajaran konvensional. Ekon \& Edem, (2018) menyatakan bahwa para pendidik seharusnya dapat mencari pembelajaran yang tepat agar dapat mereduksi miskonsepsi dalam peserta didik seperti metode kontruktivisme. Penyebab miskonsepsi tidak hanya dari proses belajar mengajar namun ada beberapa faktor yang dapat menjadikan peserta didik mengalami miskonsepsi seperti : Konsep sebelumnya, pemikiran sosial, pemikiran pribadi, minat belajar, kemampuan yang dimiliki peserta didik (Herawati, 2020).

Jahidin \& Rabani, (2018) menyatakan bahwa keberadaan miskonsepsi pada setiap peserta didik dalam materi ekosistem dipengaruhi oleh faktor kesalahpahaman materi dari jenjang pendidikan sebelumnya yang tidak memiliki ketuntasan dalam memahami materi atau sub materi dalam materi ekosistem tersebut. Hasil dalam penelitian Ahsanul Qadri Pebrianto et al., (2020) menyatakan bahwa perolehan persentase miskonsepsi tertinggi terdapat pada sub konsep interaksi antar komponen ekosistem. Pernyataan ini sesuai dengan hasil penelitian yang dilakukan peneliti pada peserta didik SMA di Kabupaten Sukabumi perolehan terbesar ditempati oleh indikator interaksi antar komponen ekosistem sebanyak $60 \%$.

Persentase miskonsepsi dalam setiap indikator pembelajaran berada pada indikator 9 mengenai pendeskripsian hubungan interaksi antar komponen ekosistem. Peserta didik memiliki persentase dengan total rata - rata dari indikator 60\%. Dapat dilihat pada Gambar 3. 


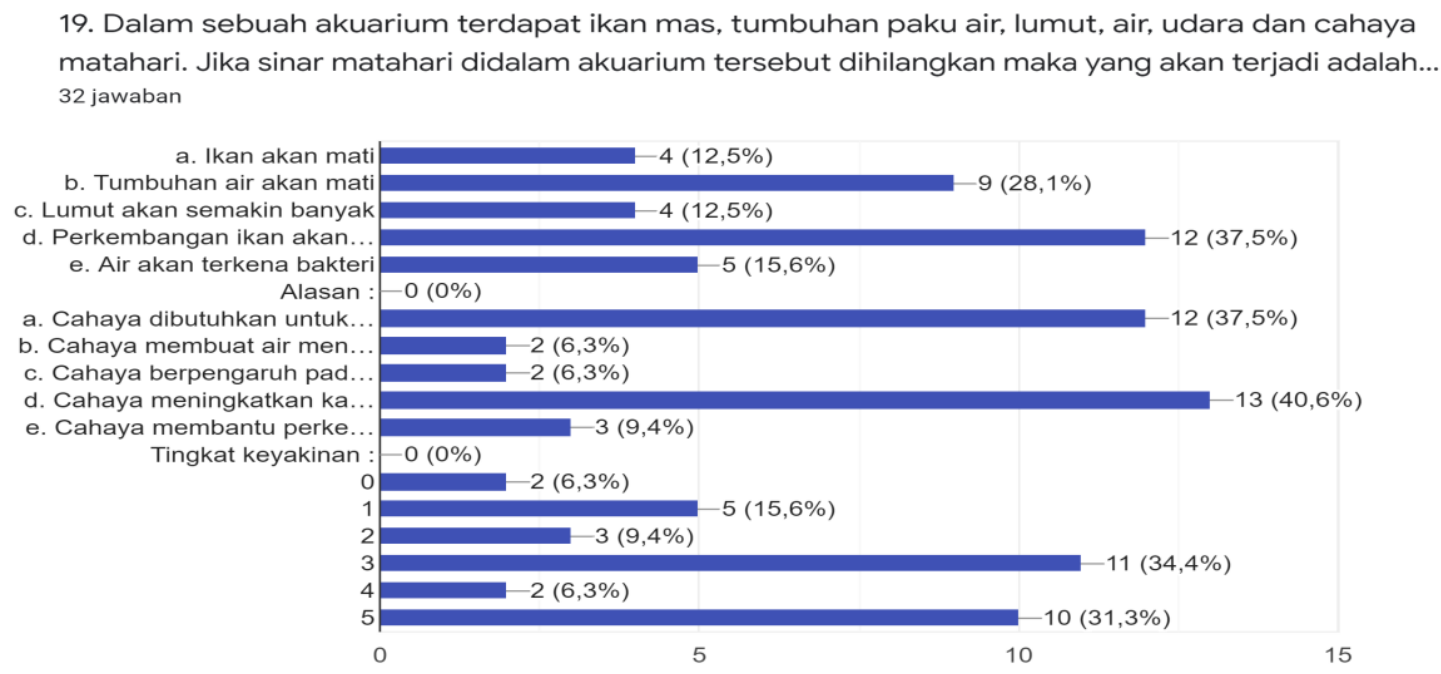

Gambar 3 Persentase Jawaban Soal Ekosistem No 19

Jawaban yang tepat untuk soal pada Gambar 3 yaitu B. Tumbuhan air akan mati dan jawaban alasan yang tepat yaitu C. Cahaya dibutuhkan untuk fotosintesis. Pada persentase memperlihatkan peserta didik sebanyak $37,5 \%$ menjawab D. Perkembangan ikan akan menurun dan untuk alasan sebesar 40,6\% peserta didik menjawab D. Cahaya meningkatkan oksigen air. Peserta didik memiliki miskonsepsi dalam indikator 19 dikarenakan pemahaman peserta didik itu sendiri, pendidik yang kurang memahami materi yang diajarkan, modul yang dipelajari pendidik, konteks keseharian peserta didik, dan metode pembelajaran yang dipakai oleh pendidik itu sendiri. Peserta didik beranggapan bahwa ketika cahaya didalam suatu akuarium hilang dapat menyebabkan ikan mengalami penurunan dalam perkembang biakannya. Namun sebenarnya ketika sebuah cahaya dalam suatu ekosistem hilang yang pertama kali terkena dampak adalah produsen yaitu tumbuhan materi ini didasari oleh konsep aliran energi pada materi ekosistem. Eromosele et al., (2016) menyatakan didalam artikelnya bahwa kesalahpahaman konsep pada materi ekologi terutama pada sub bab interaksi antar ekosistem peserta didik banyak beranggapan bahwa energi terbesar diantara rumput, domba dan manusia yang memiliki energi terbesar pertama berada pada manusia selanjutnya domba.

Pada level 2 tertinggi ada dalam indikator nomor 6 yaitu mengenai memahami pola interaksi antar organisme dengan persentase 53\%. Dapat dilihat pada Gambar 4. 


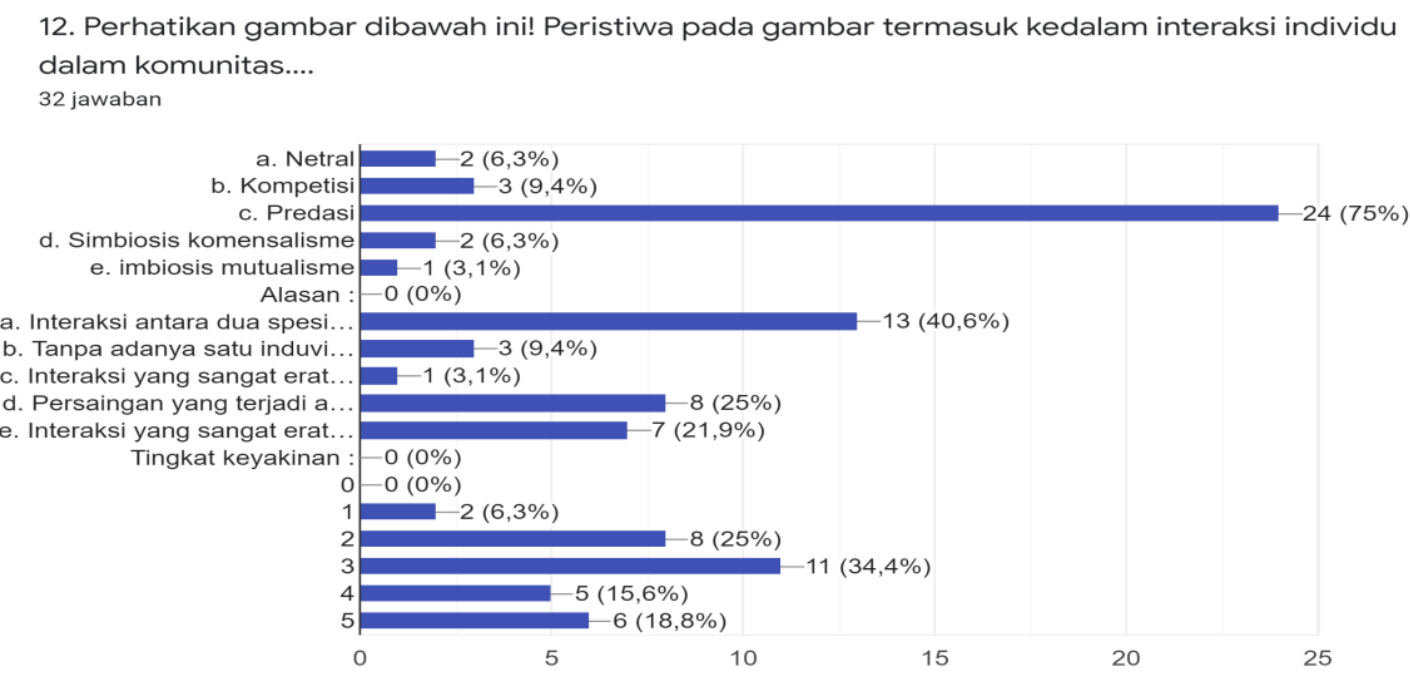

\section{Gambar 4 Persentase Jawaban Soal Ekosistem No 12}

Jawaban yang tepat pada soal nomor 12 dalam indikator 6 yaitu C. Predasi dan B. Tanpa adanya satu individu menyebabkan individu lain tidak dapat hidup. Pada hasil persentase diatas menunjukan pada jawaban pertama sebanyak $75 \%$ peserta didik menjawab benar. Namun dalam menjawab alasan peserta didik mengalami kesalahan, sebanyak 40,6\% peserta didik menjawab A. Interaksi antara dua spesies berbeda saling mempertahankan wilayah. Dalam konsep pola interaksi antar organisme predasi merupakan suatu interaksi dimana predator memangsa hewan lain untuk mempertahankan hidup. Teridentifikasi bahwa peserta didik menjawab A di karenakan terkecoh oleh gambar pada soal tersebut. Purwanti \& Kuntjoro, (2020) menjelaskan bahwa peserta didik yang memiliki jawaban terkait interaksi antar organisme disebabkan karena peserta didik memahami interaksi sebagai persaingan diantara organisme.

Diantara presentase level 1 dan 2 tertinggi perolehan nilai miskonsepsi pada peserta didik dipengaruhi oleh skala Certainty of Response Index (CRI) yang menunjukan skala diatas 2,5 antara 3-5. Skala 3 yaitu memperoleh persentase tertinggi disetiap soal. Miskonsepsi dapat disebabkan oleh konsep yang kurang tepat dan penyebab utama mikonsepsi dapat berasal dari siswa itu sendiri dari berbagai hal seperti kurangnya minat belajar, kemampuan yang rendah dan prakonsepsi. Teknik Certainty of Response Index (CRI) memberikan tingkat kepastian peserta didik dalam menjawab setiap tingkatan pada soal yang di berikan. Tingkat kepercayaan memiliki 6 tingkat yang dimulai dari 0 (Seluruh jawaban menduga - duga), 1 (Sebagian jawaban menduga - duga), 2 (Tidak yakin), 3 (Yakin), 4 (Hampir paham), 5 (Sangat paham) (Muna, 2016). Upu et al., (2020) menjelaskan tingkat kepercayaan Miskonsepsi (M) sangat perlu adanya perbaikan dikarnakan dapat menghambat penerimaan konsep baru.

Penelitian identifikasi miskonsepsi peserta didik pada materi ekosistem dapat menghasilkan setiap kategori pemahaman peserta didik. Berdasarkan informasi yang telah dijelaskan diharapkan pendidik dapat menggunakan metode dan model pembelajaran dengan tepat agar miskonsepsi tidak berada pada diri peserta didik lain. 


\section{SIMPULAN}

Pemahaman pada materi ekosistem yang terjadi pada peserta didik memiliki persentase Paham Konsep (PK) 20\%, Paham Konsep Kurang Yakin (PKKY) 6\%, Miskonsepsi (M) 32\% dan Tidak Tahu Konsep (TTK) 42\%. Adapun pemahaman menggunakan soal Two-Tier Test berbantuan Certainty of Response Index (CRI) dalam setiap indikator soal ekosistem level 1 sebanyak $60 \%$ dengan indikator dan level 2 sebanyak 53\% dengan indikator memahami pola interaksi antar organisme. Two tier test berbantuan dengan Certainty of Response Index (CRI) hanya dapat digunakan untuk pengidentifikasian miskonsepsi dan tidak dapat digunakan untuk menghilangkan miskonsepsi pada peserta didik.

\section{RUJUKAN}

Ahsanul Qadri Pebrianto, Mu'nisa, A., \& Muis, A. (2020). Identifikasi Miskonsepsi Siswa dengan Menggunakan Metode Certainty of Response Index (CRI) pada Materi Ekosistem Kelas XI MIA MAN 1 Jeneponto. Jurnal Biology Teaching and Learning, 3, 124-131.

Alonemarera, A. S. (2020). Identifikasi Miskonsepsi Mahasiswa Pendidikan Biologi Pada Materi Genetika Menggunakan Certainty of Response Indeks (Cri). Jurnal Biotek, 8(2), 109. https://doi.org/10.24252/jb.v8i2.16320

Anggrayni, S., \& Ermawati, F. U. (2019). The validity of Four-Tier's misconception diagnostic test for Work and Energy concepts. Journal of Physics: Conference Series, 1171(1), 0-13. https://doi.org/10.1088/1742-6596/1171/1/012037

Anjarsari, P. (2018). The Common Science Misconceptions in Indonesia Junior High School Students. Journal of Science Education Research, 2(1), 21-24. https://doi.org/10.21831/jser.v2i1.19329

Çepni, S., Ülger, B. B., \& Ormanci, Ü. (2017). Pre-service science teachers' views towards the process of associating science concepts with everyday life. Journal of Turkish Science Education, 14(4), 115. https://doi.org/10.12973/tused.10208

Chyleńska, Z. A., \& Rybska, E. (2019). What can we do for amphibians and reptiles at schools? Between personal conceptions, conceptual change and students' pro-environmental attitudes. Animals, 9(8). https://doi.org/10.3390/ani9080478

Desain, A., Gnss, J., Fungsi, B., Kasus, S., Geoid, T., \& Kota, G. (2019). Analisis Desain Jaring Gnss Berdasarkan Fungsi Presisi (Studi Kasus : Titik Geoid Geometri Kota Semarang). Jurnal Geodesi Undip, 8(1), 48-55.

Ekon, E. E., \& Edem, N. B. (2018). Conceptual Change Pedagogy and Its Effects On Students' Cognitive Achievement and Interest in Biology. International Journal for Cross-Disciplinary Subjects in Education, 9(2), 3407-3413. https://doi.org/10.20533/ijcdse.2042.6364.2018.0456

Eromosele, O. E., Ekholuenetale, M., \& ... (2016). On misconceptions of ecological concepts among publicsenior secondary schools students in Benin city Nigeria. International Journal of Innovation and Scientific Research, 27(1), 109-118. https://www.researchgate.net/profile/Hossain_Mohammad_Ismail2/publication/330702270_01_Inte rnational_Journal_of_Innovation_and_Scientific_Research/links/5dfb263ea6fdcc28372bf499/01International-Journal-of-Innovation-and-Scientific-Research.pdf\#page=112

Grospietsch, F., \& Mayer, J. (2018). Professionalizing pre-service biology teachers' misconceptions about learning and the brain through conceptual change. Education Sciences, 8(3), 1-23. https://doi.org/10.3390/educsci8030120 
Gurel, D. K., Eryilmaz, A., \& McDermott, L. C. (2015). A review and comparison of diagnostic instruments to identify students' misconceptions in science. Eurasia Journal of Mathematics, Science and Technology Education, 11(5), 989-1008. https://doi.org/10.12973/eurasia.2015.1369a

Hakim, A., Liliasari, \& Kadarohman, A. (2012). Student Concept Understanding of Natural Products Chemistry in Primary and Secondary Metabolites Using the Data Collecting Technique of Modified CRI. International Online Journal of Educational Sciences, 4(3), 544-553.

Herawati. (2020). Pengaruh model pembelajaran ecirr berbantuan conceptual change text terhadap miskonsepsi siswa pada konsep gerak parabola. Jakarta : UIN.

Hermita, N., Suhandi, A., Syaodih, E., Samsudin, A., Isjoni, Johan, H., Rosa, F., Setyaningsih, R., Sapriadil, \& Safitri, D. (2017). Constructing and Implementing a Four Tier Test about Static Electricity to Diagnose Pre-service Elementary School Teacher' Misconceptions. Journal of Physics: Conference Series, 895(1). https://doi.org/10.1088/1742-6596/895/1/012167

Ikram, R. L., Setiawani, S., Pambudi, D. S., \& Murtikusuma, R. P. (2018). Analisis Miskonsepsi Siswa Dalam Menyelesaikan Permasalahan Persamaan Kuadrat Satu Variabel Ditinjau Dari Perbedaan Gender. Kadikma, 9(3), 204-215.

Jahidin, J., \& Rabani, L. (2018). Miskonsepsi ekologi: Sebuah analisis hasil tes kompetisi sains Madrasah Aliyah. Jurnal Bioedukatika, 6(1), 8. https://doi.org/10.26555/bioedukatika.v6i1.7287

Kurniasih, N., \& Haka, N. B. (2017). Penggunaan Tes Diagnostik Two-Tier Multiple Choice Untuk Menganalisis Miskonsepsi Siswa Kelas X Pada Materi Archaebacteria Dan Eubacteria. Biosfer: Jurnal Tadris Biologi, 8(1), 114-127. https://doi.org/10.24042/biosf.v8i1.1270

Maesyarah, M., Jufri, A. W., \& Kusmiyati, K. (2015). Analisis Penguasaan Konsep Dan Miskonsepsi Biologi Dengan Teknik Modifikasi Certainty of Response Index Pada Siswa Smp Se-Kota Sumbawa Besar. Jurnal Pijar Mipa, 10(1), 1-6. https://doi.org/10.29303/jpm.v10i1.8

Muna, I. A. (2016). Identifikasi Miskonsepsi Mahasiswa Pgmi Pada Konsep Hukum Newton Menggunakan Certainty of Response Index (Cri). Cendekia: Journal of Education and Society, 13(2), 309. https://doi.org/10.21154/cendekia.v13i2.251

Nikmah, K., \& Suyono. (2015). Penerapan Strategi Pembelajaran Conceptual Change Untuk Meremediasi Miskonsepsi Pada Konsep Asam-Basa Siswa Kelas XII IPA SMAN 1 Waru Sidoarjo. UNESA Journal of Chemical Education, 4(3), 541-550.

Nurhidayah, L., Riandi, R., \& Solihat, R. (2020). Identifikasi miskonsepsi siswa SMA pada topik ekosistem. Assimilation: Indonesian Journal of Biology Education, 3(1), 12-17. https://doi.org/10.17509/aijbe.v3i1.23303

Patil, S. J., Chavan, R. L., \& Khandagale, V. S. (2019). Identification of Misconceptions in Science: Tools, Techniques \& Skills for Teachers. Aarhat Multidisciplinary International Education Research Journal (AMIERJ), 8(2), 466-472.

Pebrianti, D. (2014). Efektifitas Model Pembelajaran Perubahan Konseptual Untuk Mengatasi Miskonsepsi Fisika Pada Siswa Kelas X Sman 1 Praya Barat Tahun Pelajaran 2012/2013. Lensa: Jurnal Kependidikan Fisika, 2(1), 150. https://doi.org/10.33394/j-lkf.v2i1.296

Purwanti, W. M., \& Kuntjoro, S. (2020). Profil Miskonsepsi Materi Ekologi Menggunakan Four-Tier Test 
pada Peserta Didik Kelas X SMA. BioEdu: Berkala IImiah Pendidikan Biologi, 9(3), 414-421. https://ejournal.unesa.ac.id/index.php/bioedu

Qurrota, A., \& Nuswowati, M. (2018). Analisis Miskonsepsi Siswa Menggunakan Tes Diagnostic Multiple Choice Berbantuan Cri (Certainty of Response Index). Jurnal Inovasi Pendidikan Kimia, 12(1), 2108-2117.

Ramadhani, R., \& Hasanuddin, A. M. . (2016). Identifikasi Miskonsepsi Siswa Pada Konsep Sistem Reproduksi Manusia Kelas Xi Ipa Sma Unggul Ali Hasjmy Kabupaten Aceh Besar. Jurnal IImiah Mahasiswa Pendidikan Biologi, 1(1), 1-9.

Sinta, T., Lestari, N. A., Wijayati, N., \& Haryani, S. (2020). Analisis Miskonsepsi Siswa Materi Asam Basa Menggunakan Two-Tier Berbantuan CRI (Certainty of Response Index). Chemistry in Education, 9(2), 48-54.

Tayubi, Y. R. (2005). Identifikasi Miskonsepsi pada Konsep-Konsep Fisika Menggunakan Certainty of Response Index (CRI). Jurnal UPI, 24(3), 4-9.

Upu, H., Talib, A., \& Tahir, S. H. (2020). Deskripsi Tingkat Pemahaman Konsep Perpangkatan Siswa Kelas XI Menggunakan Certainty of Response Index ( CRI ). Issues in Mathematics Education, 4(1), 41-51. http://www.ojs.unm.ac.id/imed

Waluyo, E. M., Muchyidin, A., \& Kusmanto, H. (2019). Analysis of Students Misconception in Completing Mathematical Questions Using Certainty of Response Index (CRI). Tadris: Jurnal Keguruan Dan IImu Tarbiyah, 4(1), 27-39. https://doi.org/10.24042/tadris.v4i1.2988 